\title{
1,2-Polybutadiene Latices by Catalytic Polymerization in Aqueous Emulsion
}

Vincent Monteil, Amaia Bastero and Stefan Mecking*

\section{Supporting information}

a)

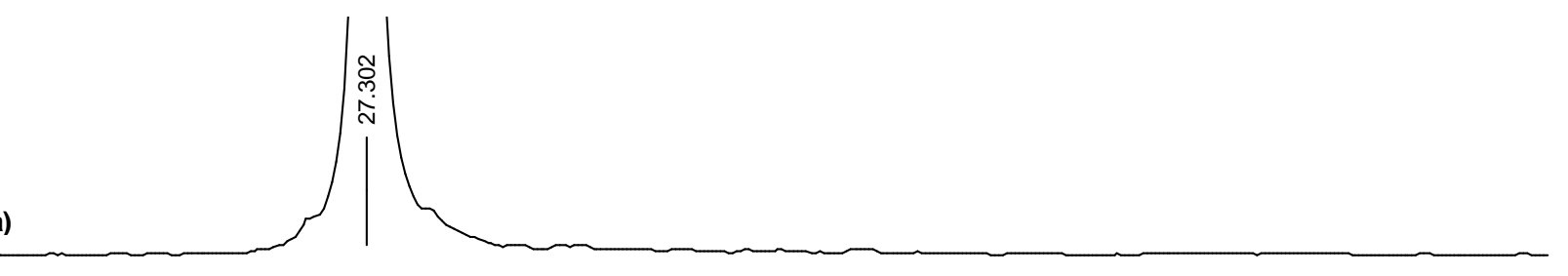

b)
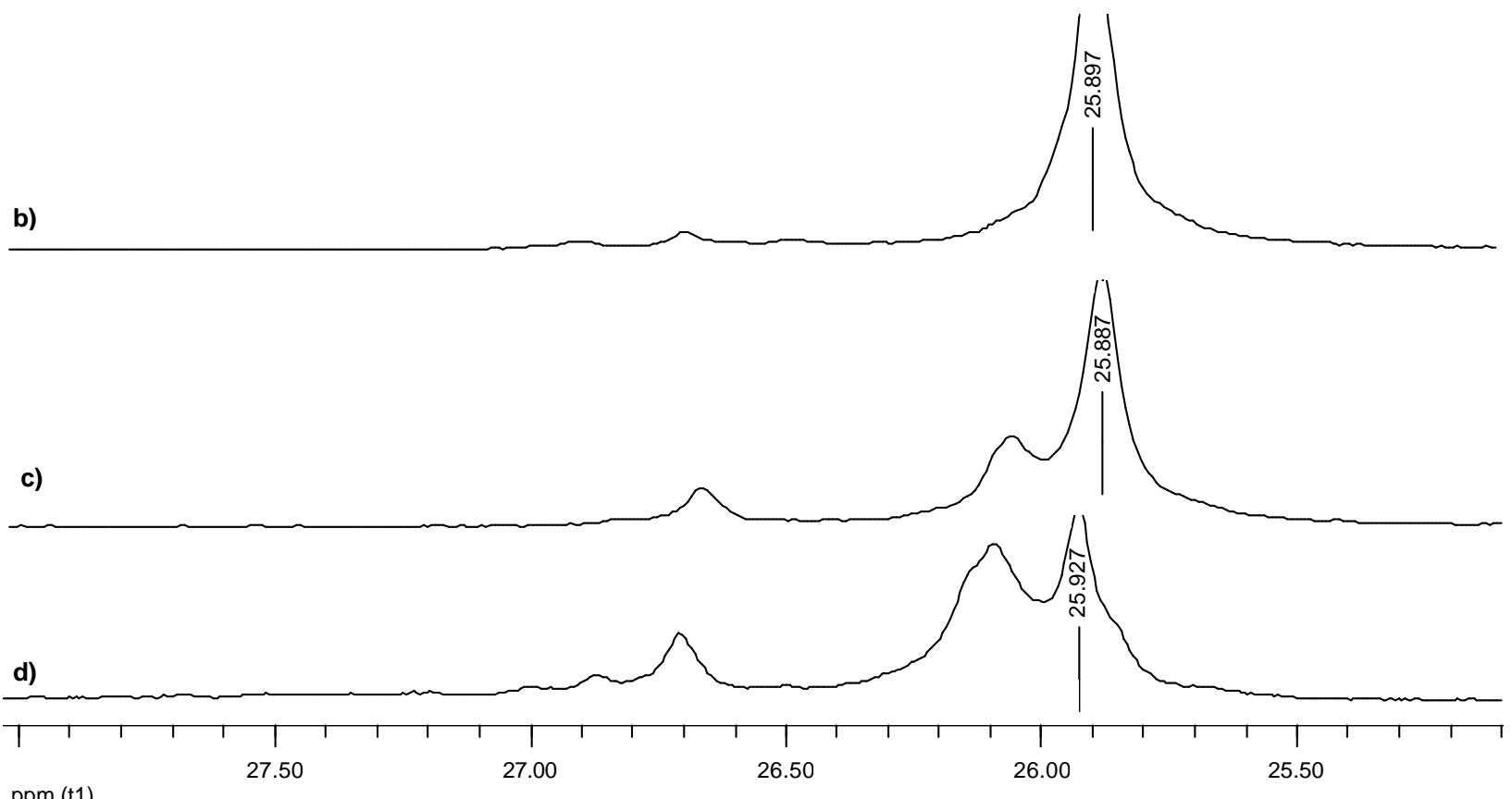

$\mathrm{ppm}(\mathrm{t} 1)$

Figure S1. Comparison of the region 28-25 ppm (pendant $\mathrm{CH}_{2}$ ) in ${ }^{13} \mathrm{C}$ NMR for tacticity determination: (a) isotactic poly(1-butene); (b) syndiotactic poly(1-butene) (prepared according Asanuma, T.; Ito, M.; Uchikawa, N.; Shiomura, T. Polym. Bull. 1991, 25, 567-70 with $\left.\left[\left\{(\mathrm{Flu}) \mathrm{CMe}_{2}(\mathrm{Cp})\right\} \mathrm{ZrCl}_{2}\right]\right)$; (c) hydrogenated 1,2-polybutadiene with 97\% 1,2-content (Bastero, A.; Mecking, S. Macromolecules, 2005, 38, 220); (d) hydrogenated 1,2polybutadiene with $85 \%$ 1,2-content. 


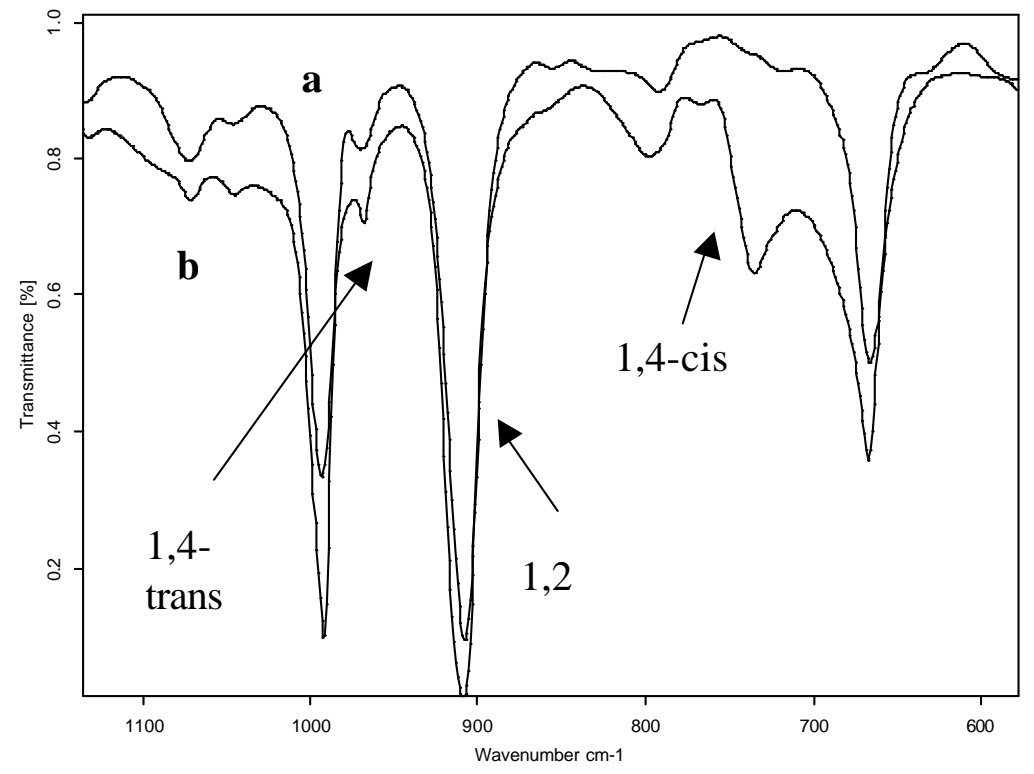

Figure S2. IR spectra of polymers obtained with. a) $\left[\mathrm{Co}\left(\mathrm{C}_{8} \mathrm{H}_{13}\right)\left(\mathrm{C}_{4} \mathrm{H}_{6}\right)\right] / \mathrm{CS}_{2}$ catalyst (Table1, entry 1), b) $\left[\mathrm{Co}\left(\mathrm{C}_{8} \mathrm{H}_{13}\right)\left(\mathrm{C}_{4} \mathrm{H}_{6}\right)\right] / \mathrm{CS}_{2} / \mathrm{DPF}$ (Table2, entry 9). 